\title{
Pós-colheita de antúrio
}

\author{
Anthurium post-harvest
}

\section{GLÁUCIA MORAES DIAS-TAGLIACOZZO}

No passado, os antúrios eram tratados com soluções contendo nitrato de prata (CASTRO et al., 1984), apesar de ainda existirem trabalhos que recomendam o uso dessas substâncias, nos últimos anos, a tendência mundial vem sendo usar soluções atóxicas.

DIAS-TAGLIACOZZO \& CASTRO (2001), verificaram que se logo após a colheita hastes de antúrio forem mantidas por 24 horas em solução de condicionamento contendo $2 \%$ de sacarose e $200 \mathrm{mg} . \mathrm{L}^{-1}$ de ácido cítrico, a longevidade de variedades importadas cultivadas e comercializadas no Brasil pode ser prolongada por 5 dias em relação às mantidas somente em água. Isso se justifica pelo fato do antúrio ser pouco sensível ao etileno e, portanto não existe necessidade de se usar nitrato de prata ou outras substâncias utilizadas para prevenir o efeito do etileno.

Na pós-colheita de variedades brasileiras não é necessário o uso de soluções conservantes, pois estas apresentam alta longevidade ( Tabela 1). Neste caso, recomenda-se manter as hastes em vasos com água limpa, a água deve ser trocada a cada 2 dias e uma vez por semana deve-se cortar $3 \mathrm{~cm}$ da base da haste. Esses procedimentos fazem com que as hastes fiquem sempre túrgidas, contribuindo deste modo para a longevidade das mesmas.

Cada cultivar possui características próprias, de modo que os sinais de senescência variam de um produto para outro. A Tabela 1 ilustra essa diversidade.

\section{LONGEVIDADE PÓS-COLHEITA}

Logo após a colheita as hastes florais devem ser levadas ao local onde serão selecionadas, tratadas e embaladas, durante esses processos deve-se ter o máximo de cuidado para não dani- ficar a haste floral, principalmente a espata que é a parte mais sensível da flor.

A turgescência na planta intacta e na flor colhida é dependente de um balanço entre a absorção e perda de água; conseqüentemente a murcha é uma das principais razões para o término da durabilidade comercial de flores colhidas (DIAS-TAGLIACOZZO \& CASTRO, 2002). Segundo VAN DOORM (1999), muitas plantas possuem características que as favorecem no mercado, entre elas está o antúrio, o qual apresenta baixas taxas de transpiração, possivelmente por possuírem poucos estômatos. Para manter a turgescência a base da haste deve ser sempre mantida em água limpa, inclusive durante o transporte e armazenamento.

Para a avaliação da manutenção da qualidade pós-colheita de antúrio deve-se adotar o critério de notas descrito a seguir, o qual foi estabelecido por DIAS-TAGLIACOZO \& CASTRO (2001):

Nota 4 - aspecto geral excelente, plantas túrgidas, espata e espádice com brilho;

Nota 3 - aspecto geral bom, início da perda de turgescência e brilho da espata;

Nota 2 - aspecto geral regular, perda de turgescência observada através da espata opaca e mudança de coloração na haste floral no local de inserção da espata;

Nota 1 - aspecto geral ruim, espata e espádice sem brilho, aspecto desbotado, haste apresenta riscas de necrose.

Nota 0 - descarte, espádice escura com ápice necrosado, espata murcha, haste amarela. Considera-se como índice de durabilidade comercial uma média igual ou superior a 3. A longevidade total compreende o período em dias do momento da colheita até o do descarte.

Em geral, as flores de origem tropical devem ser armazenadas em temperaturas acima 
A manutenção da qualidade é o objetivo das técnicas pós-colheita. Fatores anteriores à colheita como adubação adequada, condições ideais de cultivo contribuem para que o produto final tenha alta qualidade para ser mantida.

As flores cortadas são um produto altamente perecível. O manuseio incorreto pode danificar, amassar e causar manchas escuras nas flores; portanto as hastes florais devem ser cuidadosamente manuseadas para se evitar danos mecânicos e manter a qualidade adquirida no processo de produção.

\section{PONTO DE COLHEITA}

A definição do ponto de colheita é fundamental para a máxima manutenção da qualidade. Em antúrio o ponto de colheita ideal considera a firmeza do pedúnculo, a expansão da espata e as mudanças na coloração da espádice. Essas mudanças se devem à abertura das flores femininas, a qual se inicia na parte inferior da espádice e segue em direção ao ápice

Do ponto de vista da produção comercial, é a proporção de flores abertas que determina a maturidade da haste floral.

Geralmente a coloração da espádice é amarela e vai se tornando branca à medida que as flores femininas vão se abrindo e após todas as flores estarem abertas apresenta coloração verde. No entanto a mudança de coloração da espádice varia entre as diferentes cultivares. $\mathrm{Na}$ 'IAC Cananéia' a espádice é de coloração rosada, quando imatura, tornando-se mais clara quando as flores femininas estão abertas; já no caso da 'IAC Ômega' a espádice é de coloração amarelada com ápice verde e é a coloração amarelada que vai se alterando para branca no processo de maturação. Outro exemplo é a cultivar Júpiter, na qual a espádice é alaranjada e vai se tornando rosada conforme as flores vão se abrindo.

O antúrio é colhido quando metade ou três quartos da espádice apresenta alteraçãode coloração (LOPES \& MANTOVANI, 1980). Em alguns países os produtores colhem os antúrios com 4/5 da espádice com flores maduras, já os produtores do Havaí colhem a haste quando 3/4 das flores sobre a espádice estão abertas (REID \& DODGE, 2001), no entanto para exportação esses mesmos produtores utilizam hastes florais com $1 / 3$ da espádice com flores abertas (PAULL,
1982).

Colheitas precoces condicionam perdas, nestas condições as espatas não se expandem totalmente, o pedúnculo e a espata apresentam murcha precoce e a coloração da espata se altera rapidamente apresentando muitas vezes coloração azulada para as cultivares coloridas e marrom para as brancas. Colheitas tardias também comprometem a manutenção da qualidade do produto por longo período e, em ambos os casos a durabilidade é reduzida. Na maioria das vezes, quando o ponto de colheita não é o ideal, o produto comercializado apresenta vida curta, gerando insatisfação no consumidor.

\section{COLHEITA}

Nos cultivos tradicionais, as colheitas comerciais de maior valor se situam entre o quarto e quinto ano de cultivo, quando as plantas e suas flores atingem seu vigor máximo, esse tempo é reduzido quando plantas de antúrio são cultivadas pela técnica de hidroponia (TOMBOLATO et al., 2004).

O processo de colheita é manual, no qual se utilizam facas afiadas ou tesouras. Normalmente este é realizado uma ou duas vezes por semana e é dependente do número de plantas cultivadas, da demanda do mercado consumidor e do grau de maturidade das flores no momento da colheita (LOPES \& MANTOVANI, 1980).

Recomenda-se o máximo de cuidado possível durante os processos de colheita, pois o conjunto espata-espádice é facilmente danificado. Para impedir que as flores de antúrio percam sua turgescência as hastes devem ser colhidas e imediatamente colocadas em água limpa. Os recipientes onde as flores serão mantidas temporariamente, até serem embaladas e armazenadas, devem ser lavados semanalmente com solução contendo cloro, com o objetivo de evitar contaminações por microorganismos.

Para evitar os danos físicos causados por contato entre a espata e a espádice, deve-se revestir a espata com saco plástico. O mais adequado é a proteção individual de cada espata, apesar de existirem alternativas para a proteção coletiva de flores.

O uso de soluções conservantes logo após a colheita pode ser utilizado para manter a qualidade e prolongar a vida das flores cortadas. 
de $13^{\circ} \mathrm{C}$. PAULL (1987) determinou que a faixa ótima de temperatura de estocagem para flores de antúrios, das cultivares Kaumana, Nitta e Ozaki, é de $14^{\circ} \mathrm{C}$ a $17^{\circ} \mathrm{C}$. Para a 'IAC Eidibel', LEME (2004) recomenda armazenamento sob temperatura de $13^{\circ} \mathrm{C}$ e $90 \%$ de umidade. Essa recomendação, em princípio, pode ser extrapolada para todas as cultivares selecionadas pelo IAC.

\section{REFERÊNCIAS BIBLIOGRÁFICAS}

CASTRO, C.E.F.; MATTHES, L.A.F.; FERREIRA, M.A. Conservação pós-colheita de antúrio. In: CONGRESSO BRASILEIRO DE FLORICULTURA E PLANTAS ORNAMENTAIS, 4; 1983, Rio de Janeiro. Sociedade Brasileira de Floricultura e Plantas Ornamentais, EMBRAPA-DDT, 1984.

Anais. P.257-263.

DIAS-TAGLIACOZZO, G.M.; CASTRO, C.E.F. Manutenção da qualidade pós-colheita de antúrio. In: $13^{\circ}$ Congresso Brasileiro de

Floricultura e Plantas Ornamentais. São Paulo. Resumos. Campinas, 2001, p30.

DIAS-TAGLIACOZZO, G.M. \& CASTRO, C.E.F. FISIOLOGIA PÓS-COLHEITA DE ESPÉCIES ORNAMENTAIS IN: WACHOWICZ , C.M. \& CARVALHO, R.I.N. (org) - Fisiologia Vegetal: Produção e Pós-coleita. Curitiba: Champagnat, 2002, p. 359-382

LEME, J.M. Resfriamento e conservação de antúrio 'IAC Eidibel'. 2004. 104p. Dissertação (Mestrado) - Faculdade de Engenharia Agrícola, Universidade Estadual de Campinas, Campinas.

LOPES, L.C; MANTOVANI, E.C. O cultivo de antúrios. Viçosa: Universidade Federal de Viçosa, 1980. 9p. (Boletim de Extensão, 22).

PAULL, R.E. Anthurium (Anthurium andraeanum) vase life evaluation criteria. HortScience, v.17, n. 4, p.606-607, 1982.

PAULL, R.E. Effect of storage duration and temperature on cut anthurium flowers. HortScience,

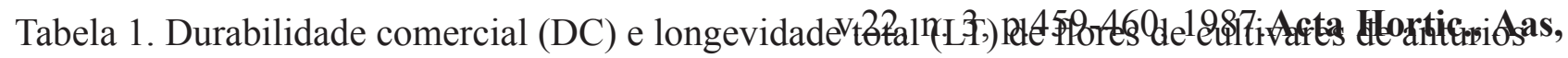
IAC.

\begin{tabular}{lcccc}
\multicolumn{1}{c}{ Cultivar } & $\begin{array}{c}\text { DC } \\
\text { (dias) }\end{array}$ & $\begin{array}{c}\text { LT } \\
\text { (dias) }\end{array}$ & & \\
'IAC Astral' & 19 & & 30 & \\
'IAC Eidibel' & 22 & & & 25 \\
'IAC Cananéia' & 15 & 25 & & \\
'IAC Omega' & 22 & 27 & \\
'IAC Iguape' & 13 & 19 &
\end{tabular}

